\title{
Pyridoxine Transport in Brush Border Membrane Vesicles of Guinea Pig Jejunum
}

\author{
Shusuke YoshIDA, Kozo HAYASHI, and Takashi KAWASAKI ${ }^{1}$ \\ Department of Biochemistry, Hiroshima University School of Medicine, \\ 1-2-3 Kasumi, Minami-ku, Hiroshima 734, Japan
}

(Received March 6, 1981)

\begin{abstract}
Summary Transport of $\left[{ }^{3} \mathrm{H}\right]$ pyridoxine was studied with membrane vesicles prepared from brush border of guinea pig jejunum, in which pyridoxal kinase was not detected. The imposition of an $\mathrm{Na}^{+}$gradient across the membrane did not affect pyridoxine transport. The equilibrium level of pyridoxine uptake decreased with increasing osmolarity of the medium, which indicates that pyridoxine is transported into the membrane vesicles. The initial rate of pyridoxine uptake increased linearly with increasing pyridoxine concentration throughout the range of $0.18 \mu \mathrm{M}$ to $7.4 \mu \mathrm{M}$ both in the presence and absence of an $\mathrm{Na}^{+}$gradient. $4^{\prime}$ Deoxypyridoxine and unlabeled pyridoxine, added in excessive amounts, did not inhibit pyridoxine transport into the membrane vesicles. These results substantiate the notion that pyridoxine passes through the brush border membrane by simple diffusion.
\end{abstract}

Key Words pyridoxine transport, simple diffusion, membrane vesicles, (guinea pig jejunum)

Transport of pyridoxine in vitro and in vivo using rat small intestine has been studied by previous investigators, and the transport has been shown to occur by simple diffusion (1-3). However, those experiments were done mostly with intact loops and tissues of the small intestine, the results obtained reflecting the movement of transport substrate from mucosal to serosal sides through the intestinal wall. Metabolic modification of the substrate during the transport should be taken into account under such experimental conditions. Therefore, the contribution of the brush border membrane to the transport cannot be assessed with intact loops or tissues of the small intestine.

The membrane vesicles from intestinal brush border have been used to study $\mathrm{Na}^{+}$-dependent uptake of amino acid, D-glucose and water-soluble vitamins (4-10).

The purpose of the present study was to investigate, based upon this knowledge, the mechanism of pyridoxine transport through the brush border

1 吉田周右，林 幸三，川崎 尚

Abbreviation: Hepes, $N$-2-hydroxyethylpiperazine- $N^{\prime}$-2-ethanesulfonic acid. 
membrane of guinea pig jejunum.

\section{MATERIALS AND METHODS}

Chemicals. All reagents were of the highest purity commercially available. [G${ }^{3} \mathrm{H}$ ]Pyridoxine hydrochloride $(1.35 \mathrm{Ci} / \mathrm{mmol})$ was obtained from the Radiochemical Centre, Amersham, England.

Isolation of brush border membrane vesicles. Membrane vesicles were prepared from guinea pig jejunum according to the procedure of Fujita et al. (11); details of this procedure have been described previously (5). This membrane vesicle preparation showed about 15-fold enrichment of alkaline phosphatase and sucrase over the starting homogenates and contained L-proline transport system as shown in a previous paper (10). Membrane vesicles were finally suspended in a medium composed of $100 \mathrm{~mm}$ D-mannitol, $0.1 \mathrm{~mm} \mathrm{MgSO}_{4}$ and $5 \mathrm{~mm}$ Tris-Hepes (pH 7.4).

Determination of pyridoxal kinase activity in brush border membrane vesicles. The reaction medium contained per ml: $0.1 \mathrm{~mm} \mathrm{ATP,} 10 \mathrm{~mm} \mathrm{MgSO}_{4}, 0.1 \mathrm{~mm}\left[{ }^{3} \mathrm{H}\right]-$ pyridoxine, $10 \mathrm{~mm}$ potassium phosphate $(\mathrm{pH} 6.5)$ and membrane vesicles (about $1 \mathrm{mg}$ of protein). After incubation for $30 \mathrm{~min}$ at $37^{\circ} \mathrm{C}$, the reaction was terminated by the addition of $1 \mathrm{ml}$ of $10 \%$ trichloroacetic acid and then the mixture was centrifuged. The supernatant was extracted 3 times with ether to remove trichloroacetic acid and then concentrated in vacuo. Phosphorylated forms of radioactive vitamin $B_{6}$ in the concentrated solution were determined after separation by paper chromatography as previously described (1).

Assay of transport activity. All assays of transport activity were carried out at $25^{\circ} \mathrm{C}$ according to the procedure used for measuring L-proline transport activity in membrane vesicles of guinea pig ileum as described previously(5). Membrane vesicles were incubated in a medium containing $100 \mathrm{~mm}$ D-mannitol, $0.1 \mathrm{mM} \mathrm{MgSO}_{4}$, $5 \mathrm{~mm}$ Tris-Hepes ( $\mathrm{pH}$ 7.4) and labeled substrate. Other additions are described in the legends of tables and figures. The transport of substrate was terminated by diluting an aliquot of the sample (approx. $100 \mu \mathrm{g}$ of membrane protein) with $40 \mathrm{vol}$. of an ice-cold buffer composed of $150 \mathrm{~mm} \mathrm{NaCl}, 50 \mathrm{mM} \mathrm{MgCl}_{2}, 30 \mathrm{~mm}$ D-mannitol and $10 \mathrm{~mm}$ Tris-Hepes ( $\mathrm{pH}$ 7.4). The diluted aliquot was immediately filtered through a Millipore filter (HAWP $0.45 \mu \mathrm{m}$ ) and washed once with $3 \mathrm{ml}$ of the same ice-cold buffer. Radioactivity retained on the filter was counted in Bray's liquid scintillation fluid.

All assays were performed in triplicate with the membrane vesicle preparation and each assay was repeated at least three times with different membrane preparations. Protein was determined according to the method of Lowry et al. (12).

\section{RESULTS}

Pyridoxal kinase activity in brush border membrane vesicles

When pyridoxal kinase activity was measured using the procedure described in 
MATERIALS AND METHODS, the reaction product, pyridoxine 5'-phosphate, and the other phosphorylated forms of vitamin $\mathrm{B}_{6}$ were not detected in the reaction medium. No kinase activity was observed even when the amount of membrane vesicles was increased up to $3 \mathrm{mg}$ of protein in the reaction mixture nor was detectable when the incubation time was prolonged to 120 min (data not shown).

This result substantiates the notion that pyridoxal kinase is not present in the membrane vesicles and that the group translocation mechanism is not operative in pyridoxine transport.

\section{Time course of pyridoxine transport}

The time course of pyridoxine transport into the membrane vesicles was examined (Fig. 1). There was no difference between the transport across the membrane in the presence of an $\mathrm{Na}^{+}$gradient and in its absence. This result suggests that pyridoxine transport into membrane. vesicles is not dependent on an $\mathrm{Na}^{+}$gradient.

\section{Effect of medium osmolarity on the uptake level of pyridoxine}

The relationship between medium osmolarity and pyridoxine uptake at 45 min was examined (Fig. 2). When the intravesicular space was decreased by increasing extravesicular medium osmolarity with D-mannitol, the uptake of pyridoxine decreased linearly. However, there was some residual uptake of radioactivity even at

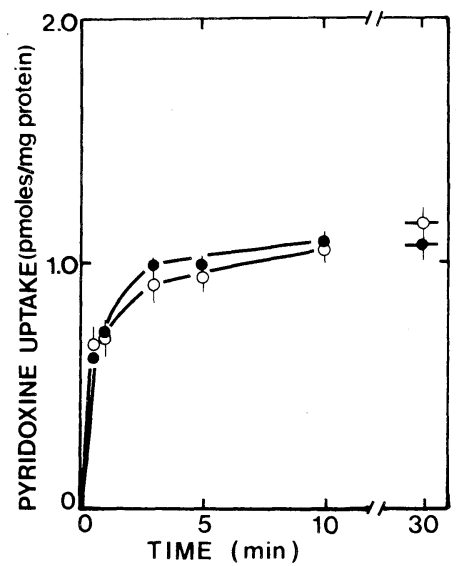

Fig. 1. Time course of pyridoxine transport. Membrane vesicles were suspended in a medium containing $100 \mathrm{mM}$ D-mannitol, $0.1 \mathrm{mM} \mathrm{MgSO}_{4}$ and $5 \mathrm{mM}$ Tris-Hepes ( $\mathrm{pH}$ 7.4). Pyridoxine transport was initiated by adding $50 \mu \mathrm{l}$ of the membrane suspension to $50 \mu \mathrm{l}$ of an incubation medium composed of $1.48 \mu \mathrm{M}\left[{ }^{3} \mathrm{H}\right]$ pyridoxine, $100 \mathrm{mM}$ Dmannitol, $0.1 \mathrm{mM} \mathrm{MgSO}_{4}, 5 \mathrm{~mm}$ Tris-Hepes (pH 7.4) and $200 \mathrm{mM} \mathrm{NaCl}$. Both the membrane suspension and the incubation medium were preincubated independently at $25^{\circ} \mathrm{C}$ before mixing, followed by further incubation at $25^{\circ} \mathrm{C}$. As control, $\mathrm{NaCl}$ in the incubation medium was replaced by $200 \mathrm{mM} \mathrm{KCl} . \mathrm{NaCl}(\bullet) ; \mathrm{KCl}(\bigcirc)$. Each point represents mean \pm S.D. of 3 determinations. 


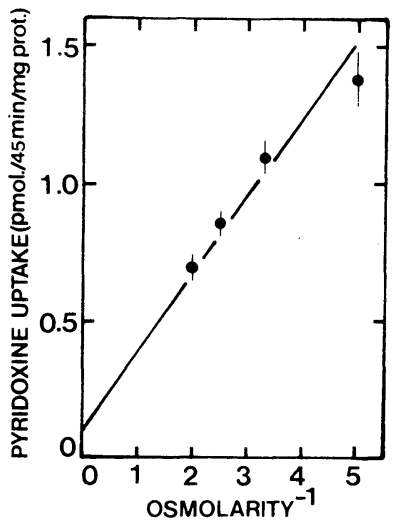

Fig. 2. Effect of medium osmolarity on pyridoxine uptake. Pyridoxine uptake was measured $45 \mathrm{~min}$ after incubation in a medium containing $0.74 \mu \mathrm{M}\left[{ }^{3} \mathrm{H}\right]$ pyridoxine, $0.1 \mathrm{mM} \mathrm{MgSO}_{4}, 5 \mathrm{~mm}$ Tris-Hepes ( $\mathrm{pH} 7.4$ ), $25 \mathrm{~mm} \mathrm{KCl}$ and D-mannitol respectively at concentrations to give the indicated osmolarities. Each point represents mean \pm S.D. of 3 determinations.

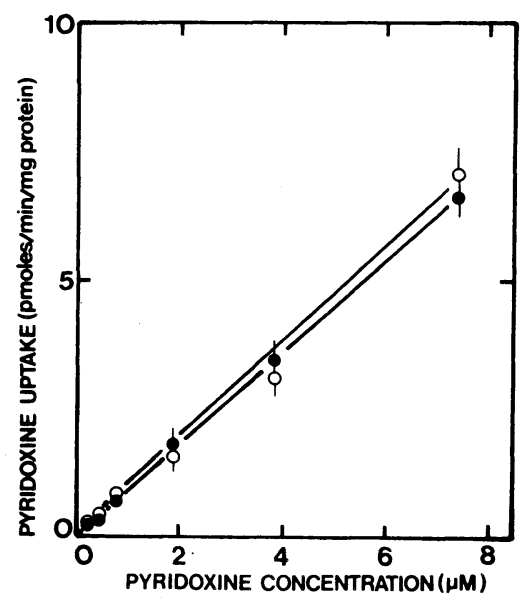

Fig. 3. Effect of pyridoxine concentration on the initial rate of transport. The transport for $1 \mathrm{~min}$ was measured in a medium containing $\left[{ }^{3} \mathrm{H}\right]$ pyridoxine at the indicated concentrations, $100 \mathrm{~mm}$ D-mannitol, $0.1 \mathrm{mM} \mathrm{MgSO}_{4}$ and $5 \mathrm{~mm}$ Tris-Hepes (pH 7.4) supplemented with either $100 \mathrm{~mm} \mathrm{NaCl}(\bullet)$ or $100 \mathrm{~mm} \mathrm{KCl}$ (O) (final concentrations). Each point represents mean \pm S.D. of 3 determinations.

infinite medium osmolarity suggesting that a portion of the uptake may have been due to binding to the membranes. This result indicates that the major portion of transported pyridoxine localizes in the intravesicular space.

Effect of pyridoxine concentration on the initial rate of transport

The effect of different concentrations of pyridoxine on the initial rate of 
Table 1. Effect of $4^{\prime}$-deoxypyridoxine and unlabeled pyridoxine on $\left[{ }^{3} \mathrm{H}\right]$ pyridoxine transport.

The transport for 1 min was measured in a medium containing 0.74 or $7.4 \mu \mathrm{M}$ [ ${ }^{3} \mathrm{H}$ ]pyridoxine, $100 \mathrm{~mm}$ D-mannitol, $0.1 \mathrm{~mm} \mathrm{MgSO}_{4}$ and $5 \mathrm{~mm}$ Tris-Hepes (pH 7.4) supplemented with $100 \mathrm{~mm} \mathrm{NaCl}$ (final concentrations). 4'-Deoxypyridoxine and unlabeled pyridoxine added were $7.4 \mu \mathrm{M}$ and $74 \mu \mathrm{M}$ (final concentrations). All values obtained for the uptake are given as mean \pm S.D. of 9 determinations (3 different membrane preparations). Results are expressed as pmol $\left[{ }^{3} \mathrm{H}\right]$ pyridoxine transported/min per mg protein.

\begin{tabular}{|c|c|c|}
\hline \multirow{3}{*}{ Additions } & \multicolumn{2}{|c|}{$\left[{ }^{3} \mathrm{H}\right]$ Pyridoxine transport } \\
\hline & \multicolumn{2}{|c|}{$\left[{ }^{3} \mathrm{H}\right]$ Pyridoxine concentration } \\
\hline & Low $(0.74 \mu \mathrm{M})$ & High $(7.4 \mu \mathrm{M})$ \\
\hline None & $0.81 \pm 0.08$ & $9.08 \pm 0.12$ \\
\hline 4'-Deoxypyridoxine $(7.4 \mu \mathrm{M})$ & $0.80 \pm 0.07$ & \\
\hline 4'-Deoxypyridoxine $(74 \mu \mathrm{M})$ & $0.75 \pm 0.05$ & $8.01 \pm 0.11$ \\
\hline Pyridoxine $(7.4 \mu \mathrm{M})$ & $0.77 \pm 0.10$ & \\
\hline Pyridoxine $(74 \mu \mathrm{M})$ & $0.78 \pm 0.03$ & $8.44 \pm 0.08$ \\
\hline
\end{tabular}

transport is illustrated in Fig. 3. The rate of pyridoxine transport increased linearly with increasing pyridoxine concentration through the range of $0.18 \mu \mathrm{M}$ to $7.4 \mu \mathrm{M}$ both in the presence and absence of an $\mathrm{Na}^{+}$gradient.

These results suggest that pyridoxine is transported into the membrane vesicles by an $\mathrm{Na}^{+}$-independent, nonsaturable process. The transport was not affected by other monovalent cations (data not shown).

Effect of $4^{\prime}$-deoxypyridoxine and unlabeled pyridoxine on $\left[{ }^{3} \mathrm{H}\right]$ pyridoxine transport

The effect of $4^{\prime}$-deoxypyridoxine and unlabeled pyridoxine on $\left[{ }^{3} \mathrm{H}\right]$ pyridoxine transport was examined (Table 1). The presence of a 10- and 100-fold excess of 4'deoxypyridoxine or unlabeled pyridoxine failed to decrease the transport of labeled pyridoxine at concentrations of $0.74 \mu \mathrm{M}$ and $7.4 \mu \mathrm{M}$. These results substantiate our contention that pyridoxine transport in the brush border membrane vesicles of guinea pig jejunum is not mediated by a specific carrier system but occurs by simple diffusion.

\section{DISCUSSION}

The absorption of pyridoxine by animal small intestine is considered to occur by a simple diffusion mechanism from previous investigations with intact loops and tissues of the small intestine (13). However, no report has been made in which brush border membrane vesicles were used to examine the mechanism of pyridoxine transport through the brush border membrane.

It is important to know whether a carrier system contributes to pyridoxine Vol. 27, No. 4, 1981 
transport across the brush border membrane. The membrane vesicles used in the present studies have been previously shown to maintain an L-proline transport system but to lack a thiamine transport system (10). The present data also give no indication of the presence of a specific pyridoxine transport system. Pyridoxal kinase, which is a possible enzyme for catalyzing group translocation if it is present, was not detected in the membrane vesicles. These results suggest that pyridoxine transport across the brush border membrane of guinea pig jejunum occurs by a simple diffusion mechanism, not by a carrier mediated process nor via group translocation.

Pyridoxine transported into the cytoplasm by the simple diffusion mechanism may be phosphorylated by pyridoxal kinase in the cytoplasm of enterocyte. Pyridoxine thus transported into cytoplasm may be transported outside of the enterocyte through the baso-lateral membrane in either a free or phosphorylated form. This exit mechanism remains to be investigated for precisely describing overall pyridoxine transport, i.e. disappearance from the mucosal lumen and arrival in the bloodstream across the enterocyte. These problems should be able to be resolved by experiments with cultured enterocyte and isolated baso-lateral membrane.

This work was supported in part by a Grant-in-Aid for Specific Project Research from the Ministry of Education, Science and Culture of Japan.

\section{REFERENCES}

1) Tsuji, T., Yamada, R., and Nose, Y. (1973): Intestinal absorption of vitamin $\mathrm{B}_{6}$. I. Pyridoxal uptake by rat intestinal tissue. J. Nutr. Sci. Vitaminol., 19, 401-417.

2) Middleton, H. M., III. (1977): Uptake of pyridoxine hydrochloride by the rat jejunal mucosa in vitro. J. Nutr., 107, 126-131.

3) Middleton, H. M., III. (1979): In vivo absorption and phosphorylation of pyridoxine $\cdot \mathrm{HCl}$ in rat jejunum. Gastroenterology, 76, 43-49.

4) Sigrist-Nelson, K., Murer, H., and Hopfer, U. (1975): Active alanine transport in isolated brush border membranes. J. Biol. Chem., 250, 5674-5680.

5) Hayashi, K., Yamamoto, S., Ohe, K., Miyoshi, A., and Kawasaki, T. (1980): $\mathrm{Na}^{+}-$ gradient-dependent transport of L-proline and analysis of its carrier system in brushborder membrane vesicles of the guinea-pig ileum. Biochim. Biophys. Acta, 601, 654-663.

6) Kessler, M., Acuto, O., Storelli, C., Murer, H., Muller, M., and Semenza, G. (1978): A modified procedure for the rapid preparation of efficiently transporting vesicles from small intestinal brush border membranes. Their use in investigating some properties of D-glucose and choline transport systems. Biochim. Biophys. Acta, 506, 136-154.

7) Hopfer, U., Nelson, K., Perrotto, J., and Isselbacher, K. J. (1973): Glucose transport in isolated brush border membrane from rat small intestine. J. Biol. Chem., 248, 25-32.

8) Murer, H., and Hopfer, U. (1974): Demonstration of electrogenic $\mathrm{Na}^{+}$-dependent Dglucose transport in intestinal brush border membranes. Proc. Natl. Acad. Sci. U.S.A., 71, 484-488.

9) Siliprandi, L., Vanni, P., Kessler, M., and Semenza, G. (1979): Na ${ }^{+}$-dependent, 
electroneutral L-ascorbate transport across brush border membrane vesicles from guinea pig small intestine. Biochim. Biophys. Acta, 552, 129-142.

10) Hayashi, K., Yoshida, S., and Kawasaki, T. (1981): Thiamine transport in the brush border membrane vesicles of the guinea-pig jejunum. Biochim. Biophys. Acta, 641, 106-113.

11) Fujita, M., Ohta, H., Kawai, K., Matsui, H., and Nakao, M. (1972): Differential isolation of microvillous and basolateral plasma membranes from intestinal mucosa: Mutually exclusive distribution of digestive enzymes and ouabain-sensitive ATPase. Biochim. Biophys. Acta, 274, 336-347.

12) Lowry, O. H., Rosebrough, N. J., Farr, A. L., and Randall, R. J. (1951): Protein measurement with the Folin phenol reagent. J. Biol. Chem., 193, 265-275.

13) Rose, R. C. (1980): Water-soluble vitamin absorption in intestine. Ann. Rev. Physiol., 42, 157-171. 